\title{
Balloon angioplasty for aortic recoarctation in children: initial and follow up results and midterm effect on blood pressure
}

\author{
Maarten Witsenburg, Salem H K The, Ad J J C Bogers, John Hess
}

\begin{abstract}
Objective-To assess the direct and follow up results of balloon angioplasty for aortic recoarctation with respect to the type of initial operation and to determine the midterm effect on systolic blood pressure. Design-Prospective study of invasive haemodynamic and angiographic data and non-invasive data on upper body blood pressure.

Setting-Tertiary referral centre for paediatric cardiology.
\end{abstract}

Subjects-24 infants and children (age $0.3-16.2$ years, mean 5.9 years) who had had surgical correction for coarctation (end to end anastomosis (14 patients) subclavian flap angioplasty (nine), patch angioplasty (one)).

Main outcome measures-Peak systolic gradient over the recoarctation and aortic diameters before and directly after angioplasty and at follow up. Upper body blood pressure before and after angioplasty and at latest follow up.

Results-Mean peak systolic gradient initially decreased from 35 (15) to 12 (9) $\mathrm{mm} \mathrm{Hg}(\mathrm{p}<0.001)$ and was 9 (10) $\mathrm{mm}$ $\mathrm{Hg}$ at follow up after $1.4(0.5)$ years. Patients with a subclavian flap repair showed a slight further decrease in the residual gradient at follow up $(p<0.05)$. The coarctation diameter increased from $5.3(2.6)$ to $7.7(2.5) \mathrm{mm}(\mathrm{p}<0.001)$, and a further increase to $9.3(2.9) \mathrm{mm}$ (p < $0.01)$ was present at follow up after 1.4 $(0.5)$ years without significant changes in other aortic diameters. Upper body systolic blood pressure decreased from 138 (24) to 115 (17) $\mathrm{mm} \mathrm{Hg}$ after balloon angioplasty, and the effect on blood pressure persisted at a mean follow up of 3.7 years. One patient died of ventricular failure. Femoral artery thrombosis occurred in three patients. In one patient a small aneurysm occurred that had not increased at follow up. In one patient restenosis after angioplasty was redilated successfully. In one patient dilatation of a residual stenosis after angioplasty failed.

Conclusion-Balloon angioplasty for recoarctation is effective and is associated with accelerated growth of the dilated segment at follow up in many patients. The complication rate is acceptable. Midterm follow up shows persistent relief of upper body hypertension in most patients.

(Br Heart $\mathcal{F} 1993 ; 70: 170-174)$
Restenosis after surgical management of coarctation of the aorta, either end to end anastomosis or subclavian flap angioplasty, remains a clinical problem and is seen particularly in patients who had surgical repair during infancy. ${ }^{1}$ Balloon angioplasty has gained wide acceptance as an alternative to repeat surgery, and results are satisfactory..$^{2-8}$ Follow up after angioplasty focuses on the incidence of restenosis and aneurysm formation. We evaluated the haemodynamic and angiographic data in 24 patients with coarctation restenosis at balloon angioplasty and up to two years afterwards, with special regard to the type of surgery that had initially been performed. Clinical follow up to five years focused on the effect on upper body systolic blood pressure.

\section{Patients and methods}

From October 1986 to December 1989, 24 patients underwent balloon angioplasty for aortic recoarctation. Recoarctation was defined on the basis of absent or diminished femoral artery pulses, upper body hypertension, and a pressure gradient of greater than $20 \mathrm{~mm} \mathrm{Hg}$ between the upper and lower part of the body. ${ }^{89}$ The mean age at angioplasty was 5.9 years (range $0 \cdot 3-16 \cdot 2$ ). There were 12 boys and 12 girls. Surgical repair for coarctation had been performed $0 \cdot 2-15 \cdot 3$ years earlier (mean 6.6 years). The type of repair was resection of the coarctation and end to end anastomosis in 14 patients, subclavian flap angioplasty in nine, and patch angioplasty in one. The choice for the type of correction was not based on anatomical differences but reflected surgical preference. In three patients the end to end anastomosis was performed via a median sternotomy in combination with an intracardiac repair. Five of the patients had an isolated coarctation and 19 had associated cardiac lesions (table). One patient died two days after balloon angioplasty. One patient was lost to follow up. Invasive follow up studies were performed in the remaining 22 patients after $0.4-2.6$ years $(1 \cdot 4)$. Clinical follow up studies were performed yearly up to $1 \cdot 7-5 \cdot 5$ years $(3 \cdot 7)$.

Cardiac catheterisation was performed routinely under general anaesthesia. Peak systolic pressure differences were measured with fluid filled catheters. A cross sectional aortogram was obtained. Diameter was measured from the lateral angiogram directly proximal to the coarctation site, at the level of the coarctation, just below the coarctation 


\begin{tabular}{|c|c|c|c|c|c|}
\hline Case No & Sex & $\begin{array}{l}\text { Age at initial } \\
\text { surgery }(y)\end{array}$ & Type of surgery & Additional diagnosis & $\begin{array}{l}\text { Age at balloon } \\
\text { angioplasty }(y)\end{array}$ \\
\hline 1 & $\mathbf{F}$ & $3 \cdot 8$ & End to end & Ventricular septal defect & $13 \cdot 3$ \\
\hline 2 & $\mathbf{M}$ & $1 \cdot 3$ & End to end & VAS & $14 \cdot 4$ \\
\hline 3 & $\mathbf{F}$ & $0 \cdot 6$ & End to end & Ventricular septal defects & $12 \cdot 6$ \\
\hline 4 & $\mathrm{~F}$ & $0 \cdot 2$ & Subclavian flap & Ventricular septal defects & $7 \cdot 6$ \\
\hline 5 & $\mathbf{F}$ & 0.5 & End to end & Ventricular septal defect, subvalvar & 0.9 \\
\hline 6 & $\mathbf{M}$ & $0 \cdot 0$ & Subclavian flap & Atrial septal defect, ventricular & \\
\hline & & & & septal defect, ductus arteriosus & $0 \cdot 7$ \\
\hline 7 & $\mathbf{F}$ & 0.0 & End to end & Ductus arteriosus, incomplete & \\
\hline 8 & $\mathbf{M}$ & $4 \cdot 4$ & End to end & double arch & $\begin{array}{r}0.3 \\
14 \cdot 8\end{array}$ \\
\hline 9 & $\mathbf{M}$ & $1 \cdot 3$ & End to end & Atrial septal defects, PAPVC & $15 \cdot 5$ \\
\hline 10 & $\mathbf{M}$ & $0 \cdot 0$ & Subclavian flap & Ventricular septal defect & $5 \cdot 8$ \\
\hline 11 & $\mathbf{M}$ & $0 \cdot 0$ & Reversed subclavian flap & - & $3 \cdot 1$ \\
\hline 12 & $\mathbf{M}$ & $2 \cdot 3$ & End to end & - & $15 \cdot 3$ \\
\hline 13 & $\mathbf{F}$ & 0.9 & End to end & Ventricular septal defect & $16 \cdot 2$ \\
\hline 14 & $\mathbf{M}$ & $0 \cdot 0$ & Subclavian flap & & $6 \cdot \overline{2}$ \\
\hline 15 & $\mathbf{F}$ & $4 \cdot 8$ & End to end via median sternotomy & $\begin{array}{l}\text { Ventricular septal defects, } \\
\text { subvalvar aortic stenosis }\end{array}$ & $5 \cdot 3$ \\
\hline $\begin{array}{l}16 \\
17\end{array}$ & $\mathbf{F}$ & $6 \cdot 0$ & End to end & - . & $14 \cdot 6$ \\
\hline 17 & $\mathbf{M}$ & $0 \cdot 2$ & Patch & $\begin{array}{l}\text { Atrial septal defect, ventricular } \\
\text { septal defects, ductus arteriosus }\end{array}$ & $8 \cdot 3$ \\
\hline 18 & $\mathbf{M}$ & $0 \cdot 0$ & End to end via median sternotomy & $\begin{array}{l}\text { Atrial septal defect, ventricular } \\
\text { septal defect, ductus arteriosus }\end{array}$ & 0.9 \\
\hline 19 & $\mathbf{F}$ & $0 \cdot 0$ & End to end via median sternotomy & $\begin{array}{l}\text { Ventricular septal defect, } \\
\text { subvalvar aortic stenosis }\end{array}$ & $0 \cdot 3$ \\
\hline 20 & $\mathbf{F}$ & $0 \cdot 1$ & Subclavian flap & Ventricular septal defect & $7 \cdot 5$ \\
\hline 21 & $\mathbf{M}$ & $0 \cdot 0$ & Reversed subclavian flap & Subvalvar aortic stenosis & $7 \cdot 8$ \\
\hline 22 & $\mathbf{F}$ & $0 \cdot 0$ & End to end & Ventricular septal defect, & 6.6 \\
\hline 23 & $\mathbf{F}$ & $0 \cdot 0$ & Subclavian flap & Ventricular septal defect, subvalvar & \\
\hline 24 & $\mathbf{F}$ & 0.0 & Subclavian flap & puin & $\begin{array}{l}0.2 \\
5.6\end{array}$ \\
\hline
\end{tabular}

PAPVC, partial anomalous pulmonary nervous connection.

site, and at the level of the diaphragm. Heparin 100 Units/kg was administered intravenously. Balloon angioplasty was performed by a transfemoral approach with a single balloon. The balloon was three times the coarctation diameter and did not exceed $120 \%$ of the proximal aortic diameter. ${ }^{3}$ After the balloon angioplasty repeat measurements and angiography were performed. All angiograms were thoroughly reviewed for signs of intimal dissection. Complications of the procedure were listed. At follow up the pressure withdrawal curves over the dilated site were recorded and cross sectional angiography was performed in projection angles equal to those at the time of balloon angioplasty. The
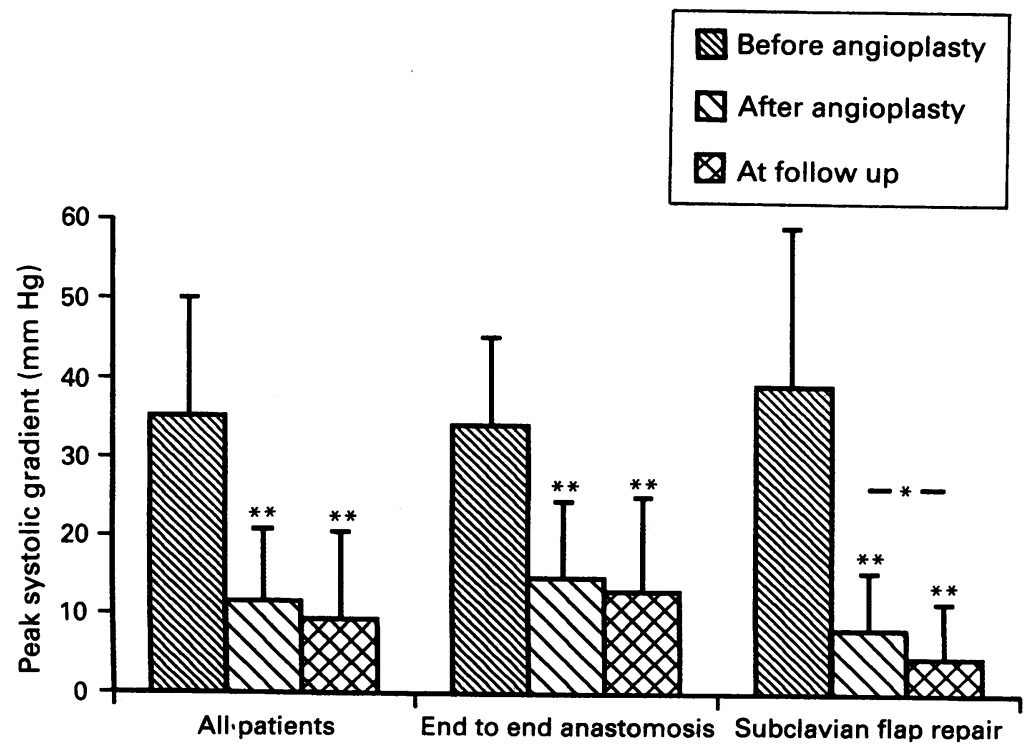

Figure 1 Invasive mean peak systolic gradient over aortic recoarctation before and after balloon angioplasty and at follow up (mean 1.4 years) in all patients and in those with end to end anastomosis and subclavian flap angioplasty $\left({ }^{\star} p<0.05, \star_{p}<0.01\right)$. diameter of the aorta was measured at the four levels. In case of intimal dissection cross sectional angiography was repeated again after one year to check for further aneurysm formation. Resting blood pressure was measured oscillometrically (Dinamap) in the right arm before and on the day after balloon angioplasty and then yearly in combination with a clinical examination.

DATA ANALYSIS

Statistical analysis of the data was performed using Student's $t$ test for paired or unpaired observations. Values are expressed as means and standard deviations or ranges when appropriate. Differences were considered significant when a $\mathrm{p}$ value was less than $0 \cdot 05$.

\section{Results}

INVASIVE STUDIES

\section{Haemodynamic data}

The peak systolic gradient over the stenosis before balloon dilatation was 35 (15) $\mathrm{mm} \mathrm{Hg}$ and decreased to 12 (9) $\mathrm{mm} \mathrm{Hg}(\mathrm{p}<0.001)$ after dilatation (fig 1 ). The predilatation gradient in patients with an end to end anastomosis was not significantly different from that in patients with a subclavian flap repair (34 (11) v 39 (19) $\mathrm{mm} \mathrm{Hg}$ ), and there was no difference after dilatation (15 (10) $v 8$ (8) $\mathrm{mm} \mathrm{Hg}$; NS). In all patients the peak systolic pressure gradient at follow up after $1.4(0.5)$ years was 9 (10) $\mathrm{mm} \mathrm{Hg}$ and not significantly different from the value directly after dilatation. The residual gradient at follow up in patients who had undergone dilatation after an end to end anastomosis was not significantly different from that in patients after a subclavian flap angioplasty (13 (12) $v 5$ (7) $\mathrm{mm} \mathrm{Hg}$ ). Only the patients with a subclavian 
flap, however, showed a significant but mild further decrease in residual gradient when compared with the result directly after dilatation (5 (7) $v 8$ (8) $\mathrm{mm} \mathrm{Hg}$; $\mathrm{p}<0.05)$.

Directly after the balloon angioplasty the peak systolic pressure difference was less than $10 \mathrm{~mm} \mathrm{Hg}$ in 12 patients, between 10 and 20 $\mathrm{mm} \mathrm{Hg}$ in six, and $20 \mathrm{~mm} \mathrm{Hg}$ or more in six. Of the 22 patients at follow up, 17 had a gradient of less than $10 \mathrm{~mm} \mathrm{Hg}$, one a gradient between 10 and $20 \mathrm{~mm} \mathrm{Hg}$, and four a gradient of $20 \mathrm{~mm} \mathrm{Hg}$ or more. An end to end anastomosis had been performed in three of the four patients with a residual gradient of more than $20 \mathrm{~mm} \mathrm{Hg}$. In one of these three patients dilatation was repeated successfully, but in the two others an elongated small segment of the distal arch was not amenable for repeat balloon angioplasty. The initial result of the dilatation in these patients had been disappointing too. Repeat dilatation was not successful in one patient who had initially had a subclavian flap repair and in whom the peak systolic gradient had reduced from $43 \mathrm{~mm}$ $\mathrm{Hg}$ to $23 \mathrm{~mm} \mathrm{Hg}$ and to $20 \mathrm{~mm} \mathrm{Hg}$ at follow up.

\section{Coarctation diameter}

The coarctation diameter increased from $5 \cdot 3$ $(2.6) \mathrm{mm}$ to $7.7 \quad(2.5) \mathrm{mm}(\mathrm{p}<0.001)$ directly after dilatation and to $9.3(2.9) \mathrm{mm}$ $(p<0.01)$ at follow up after $1.4(0.5)$ years. Proportionally the mean increase was $170 \%$ (range $106 \%-369 \%$ ) of the initial diameter directly after the balloon angioplasty and $203 \%$ (range $115 \%-383 \%$ ) at follow up. There was no significant change of the proximal and distal aortic diameters either at angioplasty or at follow up (fig 2). Furthermore, coarctation diameter was not significantly different in patients with an end to end anastomosis or a subclavian flap repair.

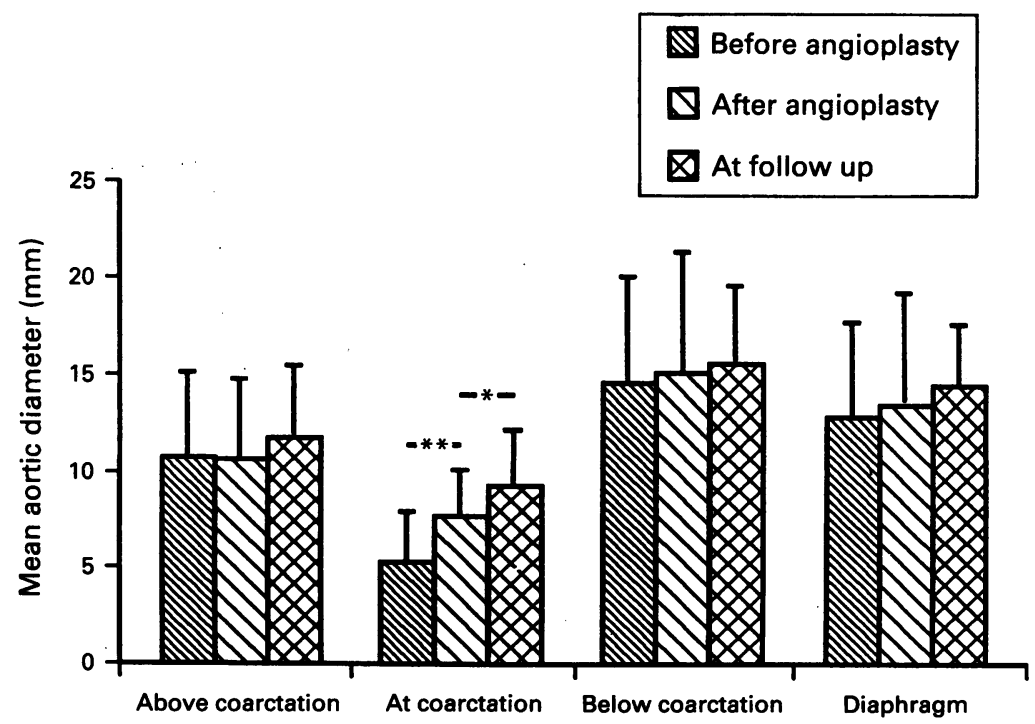

Figure 2 Angiographically determined mean aortic diameters at four levels in all patients before and after balloon angioplasty for aortic recoarctation and at follow up (mean 1.4 years) $\left({ }^{*} p<0.01,{ }^{*} *_{p}<0.001\right)$.

\section{COMPLICATIONS}

One patient, who also had severe subaortic obstruction and poor left ventricular function, died 36 hours after emergency balloon angioplasty from persistent heart failure. Angiographically the result of the balloon angioplasty was good. Postmortem examination was not permitted. Intimal dissection leading to a small aneurysm was seen in one patient, who had initially had a subclavian flap repair operation. The ratio of the balloon and coarctation diameters was 1.6 in this patient. The aneurysm was small and had not increased in size at follow up (fig 3). No new aneurysms were observed at follow up in the other patients. Balloon rupture occurred in four patients, including the patient who presented with an aneurysm. In a 13 year old girl a circular tear in the balloon complicated removal of the catheter, leading to femoral artery thrombosis. In contrast with our current policy she did not receive any anticoagulant or thrombolytic treatment. ${ }^{10}$ At follow up she persistently had diminished arterial pulsations of the leg without any other signs of impaired circulation. Two other children developed femoral artery thrombosis. One of them, a 3 month old girl, was treated with heparin alone but without success, and the other was successfully treated with streptokinase. None of the patients lost excessive

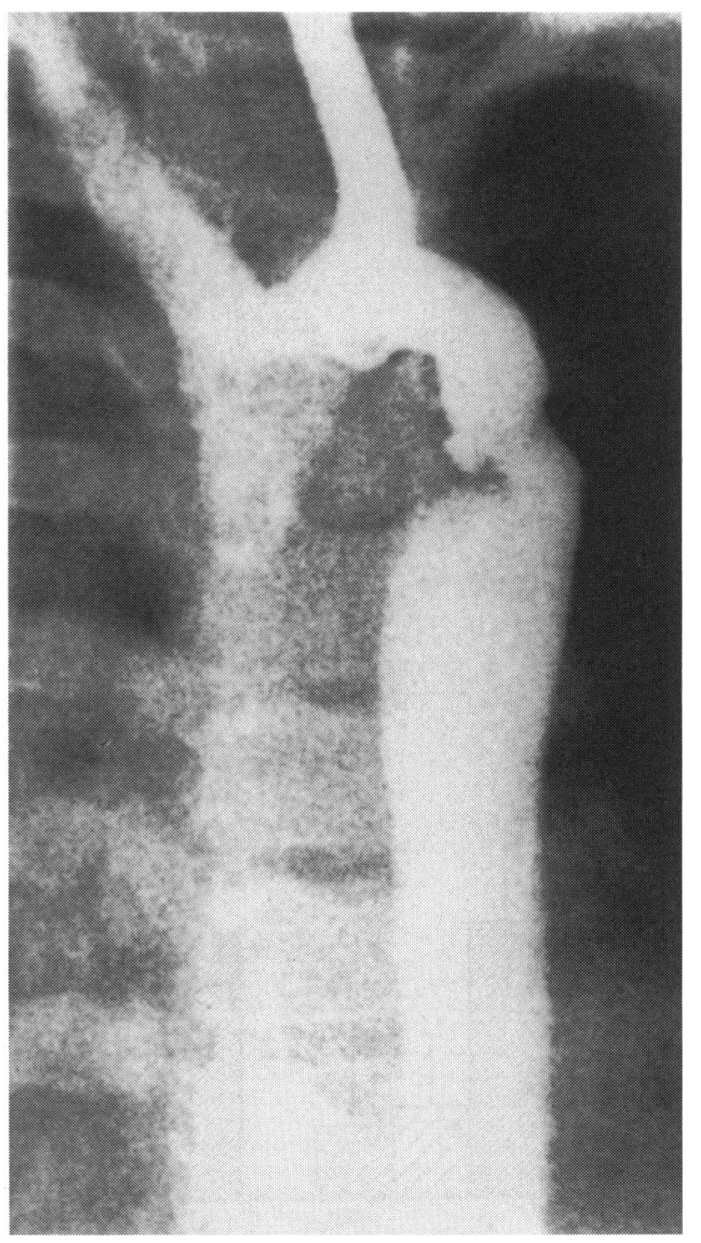

Figure 3 Aneurysm at medial site after balloon angioplasty in patient who had initially had subclavian flap repair. At follow up no enlargement of aneurysm and no residual gradient were seen. 
amounts of blood. One patient experienced a transient hemianopsia, which had completely resolved after two days. We observed no cases of paradoxical hypertension after balloon angioplasty.

\section{BLOOD PRESSURE}

Peak systolic blood pressure measured in the right arm was 138 (24) $\mathrm{mm} \mathrm{Hg}$ before balloon angioplasty and 115 (17) $\mathrm{mm} \mathrm{Hg}$ afterwards $(p<0.01)$. Except for the patient with cardiac failure, systolic blood pressure was above the 95th centile for age before dilatation. ${ }^{910}$ After the intervention systolic blood pressure was still above the 95th centile in four patients. At the latest follow up (mean 3.7 years, range $1.7-5.5$ ) mean peak systolic blood pressure was higher than that early after balloon angioplasty $(125(21) \mathrm{mm} \mathrm{Hg}$; $\mathrm{p}<0.05$ ) (fig 4) but still lower compared with the value before angioplasty $(p<0.01)$. In patients who had initially been treated by end to end anastomosis blood pressure at the latest follow up did not differ from the value before angioplasty, whereas in patients initially given subclavian flap repair blood pressure was still significantly lower (fig 4). There were no significant differences in blood pressure between the patients with an end to end anastomosis and those with a subclavian flap angioplasty before and directly after balloon angioplasty or at the latest follow up. Systolic blood pressure at latest follow up was above the 95th centile in five patients (three had had end to end anastomosis, two subclavian flap repair). Clinical signs of recurrence of coarctation after balloon angioplasty were not observed, except in the patient who underwent a successful repeat dilatation, in whom the effect persisted at follow up.

\section{Discussion}

The occurrence of restenosis after surgical repair for coarctation of the aorta remains a limited but recurring problem in clinical

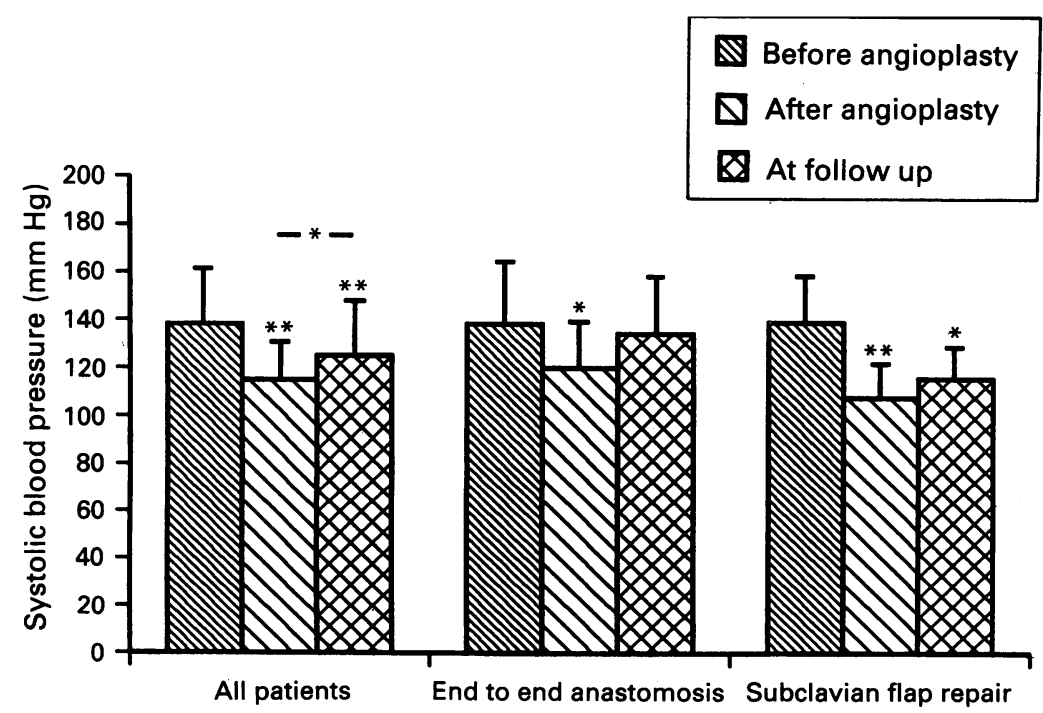

Figure 4 Systolic blood pressure measured in right arm before and after balloon angioplasty and follow up (mean 3.7 years) in all patients and in those with end to end anastomosis and subclavian flap angioplasty $\left({ }^{*} p<0.05, \star^{*} p<0.01\right)$. practice. ${ }^{1}$ Different surgical approaches have been advocated and used by surgeons, which was reflected in our study. Initially an end to end repair was favoured, but then gradually subclavian flap angioplasty was used more often in infants and gave reasonable results. In the past few years we expected that an extended end to end repair could overcome the problems of restenosis. It still occurs, however, especially in infants when an intracardiac defect and a coarctation via a median sternotomy are operated on at the same time. ${ }^{11}$ Our results confirm that balloon angioplasty for recoarctation directly results in a substantial reduction of the invasively measured mean peak systolic gradient $(67 \%)$. The invasively measured gradients were obtained during general anaesthesia, which may have led to underestimation of the gradient because of factors such as diminished cardiac output and vasodilatation. Therefore changes in the peak systolic pressure in the ascending aorta are not discussed here. Our haemodynamic data on the coarctation gradient, however, were comparable with those in previous studies. ${ }^{1-8}$ After a mean follow up of 1.4 years a considerable further decrease in the invasively obtained residual gradient was observed in most patients. Restenosis after the balloon dilatation was observed in only one patient after an end to end type repair. Residual stenosis with a gradient of $20 \mathrm{~mm}$ $\mathrm{Hg}$ or more at follow up was observed in three patients. The mean increase in the coarctation diameter was $170 \%$ after balloon angioplasty. The follow up results, showing a further increase in diameter, were consistent with the haemodynamic findings. In addition, there proved to be an accelerated growth of the dilated segment in many patients.

After surgery for coarctation there remains an increased risk for cardiovascular complications and hypertension. ${ }^{12}{ }^{13} \mathrm{~A}$ higher probability of death in adult life is associated with persistent high blood pressure after coarctation repair. The effect of balloon angioplasty on upper body systolic blood pressure, one of the major reasons for treatment of recoarctation, persisted in most of our patients at longer term clinical follow up. As absolute blood pressure increases with age in children, the clinical relevance of these measurements was evaluated on the basis of blood pressure centiles for age.

Some of our findings suggest that the results of balloon dilatation for recoarctation are slightly better after subclavian flap angioplasty. This difference related to the initial type of surgery has not been observed in previous studies ${ }^{68}$ and may reflect the difference in morphological substrate. In our study, however, the patient groups were not comparable according to age at the time of balloon angioplasty. In addition, our finding is unlikely to influence surgical preference.

We observed few complications of angioplasty. The cause of death in the patient who died was probably not related to the angioplasty. Femoral artery problems were observed in three patients, in two of them 
during the first year of our experience. Although the use of low profile balloons during balloon angioplasty and of thrombolytic agents when arterial thrombosis is suspected can reduce the incidence of femoral artery complications, such problems are unlikely to be eliminated completely. If possible the balloon angioplasty should be postponed until the patient weighs more than $10 \mathrm{~kg} .{ }^{14}$ Intimal dissection and subsequent aneurysm formation directly after balloon angioplasty or later are mainly observed when this technique is used in primary coarctation. ${ }^{15}$ Aneurysms may occur after angioplasty for recoarctation. ${ }^{68}$ In our study such an aneurysm occurred in a patient with a subclavian flap repair; the balloon ruptured during inflation and the aneurysm occurred opposite the site of the flap. The presence of scar tissue around the aorta, which should prevent aneurysm formation, may be less circumferential in patients after a subclavian flap repair than after an end to end anastomosis. Although the aneurysm had not enlarged at follow up, the long term clinical importance of such aneurysms remains unknown. A recent report of a fatal rupture during balloon angioplasty for recoarctation in a patient who had initially had a patch angioplasty emphasises the risk of balloon dilatation in this type of repair. ${ }^{16}$ Regular follow up is necessary. Magnetic resonance imaging is suggested as an alternative for cross sectional angiography, but no studies comparing both techniques with respect to aneurysms have yet been reported. ${ }^{17}$

In conclusion, our results show that balloon angioplasty for recoarctation of the aorta can be performed with good results at midterm clinical follow up both after an end to end anastomosis and after a subclavian flap repair. The reduction of upper body blood pressure in many patients is important for diminishing the long term negative effects on cardiac function.

1 Beekman RH, Rocchini AP, Behrendt DM, Bove EL Macdonald Dick II, Crowley DC, et al. Long-term outcome after repair of coarctation in infancy: subclavian flap angioplasty does not reduce the need for reoperation. $\mathcal{f} \mathrm{Am}$ Coll Cardiol 1986;8:1406-11.

2 Kan JS, White RI Jr, Mitchell SE, Farmlett EJ, Donahoo JS, Gardner TJ. Treatment of restenosis of coarctation by percutaneous transluminal angioplasty. Circulation 1983;68:1087-94.

3 Hess J, Mooyaart EL, Busch HJ, Bergstra A, Landsman MLJ. Percutaneous transluminal balloon angioplasty in restenosis of coarctation of the aorta. Br Heart $f$ restenosis of coarc

4 Saul JP, Keane JF, Fellows KE, Lock JE. Balloon dilatation angioplasty of postoperative aortic obstructions. Am $\mathcal{F}$ Cardiol 1987;59:943-8.

5 Cooper SG, Sullivan ID, Wren C. Treatment of recoarctation: balloon dilatation angioplasty. $\mathcal{F} \mathrm{Am}$ Coll Cardio 1989;14:413-9.

6 Hellenbrand WE, Allen HD, Golinko RJ, Hagler D, Lutin W, Kan J. Balloon angioplasty for aortic recoarctation results of valvuloplasty and angioplasty of congenital anomalies registry. $A m \mathcal{F}$ Cardiol 1990;65:793-7.

7 Rao PS, Wilson AD, Chopra PS. Immediate and followup results of balloon angioplasty of postoperative recoarctation in infants and children. Am Heart $\mathscr{f}$ 1990;120:1315-20.

8 Anjos R, Qureshi SA, Rosenthal E, Murdoch I, Hayes A Parsons J, Baker EJ, Tynan M. Determinants of hemodynamic results of balloon dilatation of aortic recoarctation. Am $\mathcal{\exists}$ Cardiol 1992;69:665-71.

9 Task Force Working Group. Report of the Task Force on Blood Pressure Control in Children. Pediatrics 1987;79: $1-25$.

10 De Man SA, André JL, Bachmann H, Grobbee DE, Ibsen $\mathrm{KK}$, Laaser $\mathrm{U}$, et al. Blood pressure in childhood pooled findings of six European studies. $\mathcal{f}$ Hyperten 1991;9:109-14

11 Hazekamp MG, Quaegebeur JM, Singh S, Hardjowijono R, Bogers AJC, Ottenkamp J, et al. One stage repair of aortic arch anomalies and intracardiac defects. Eur $\mathscr{f}$ Cardiothorac Surg 1991;5:283-7.

12 Cohen M, Fuster V, Steele PM, Driscoll D, McGoon DC. Coarctation of the aorta; long-term follow-up and prediction of outcome Circulation 1989;80:840-5.

13 Bobby J, Emani JM, Farmer RDT, Newman CGH Operative survival and 40 year follow up of surgical Operative survival and 40 year follow up of surgica
repair of aortic coarctation. Br Heart $\mathcal{F} 1991 ; 65: 271-6$.

14 Brus F, Witsenburg M, Hofhuis WJD, Hazelzet JA, Hes J. Streptokinase treatment for femoral artery thrombosis after arterial cardiac catheterisation in infants and children. Br Heart $\mathcal{F}$ 1990;63:291-4.

15 Tynan M, Finley JP, Fontes V, Hess J, Kan J. Balloon angioplasty for the treatment of native coarctation: results of valvuloplasty and angioplasty of congenital anomalies registry. $A m$ F Cardiol 1990;65:790-2.

16 Balaji S, Oommen R, Rees PG. Fatal aortic rupture during balloon dilatation of recoarctation. $\mathrm{Br}$ Heart 1991;65:100-1.

17 Soulen RL, Kan J, Mitchell S, White AI. Evaluation of balloon angioplasty of coarctation restenosis by magnetic resonance imaging. Am $¥$ Cardiol 1987;60:343-5. 